\title{
Prevalence and risk factors of preoperative deep venous thrombosis in closed patella fracture: a prospective cohort study
}

\author{
Zhanchao Tan ${ }^{1}$, Hongzhi Hu${ }^{2}$, Zhongzheng Wang ${ }^{1}$, Yuchuan Wang ${ }^{1}$ and Yingze Zhang ${ }^{1,3,4^{*}}$
}

\begin{abstract}
Background: The preoperative prevalence of deep venous thromboembolism (DVT) of patella fracture is not well established. The study aimed to investigate the preoperative prevalence, the associated risk factors, and the locations of deep venous thrombosis (DVT) in patients with closed patella fracture.

Methods: Patients who sustained closed patella fracture between January 1, 2016, and April 1, 2019, were included. Blood analyses and ultrasonography of bilateral lower extremities were routinely performed. Data of demographics, comorbidities, mechanism of injury, fracture type, total hospital stay, time from injury to DVT, and laboratory indexes were prospectively collected and compared between groups with and with non-DVT. Multivariate logistic regression analyses were performed to determine the independent risk factors of DVT.

Results: Among the study cohort of 790 patients, 35 cases occurred in preoperative DVTs, indicating a prevalence of $4.4 \%$, with $3.2 \%$ distal and 1.2\% proximal DVT. Age $\geq 65$ years old $(\mathrm{OR}, 3.0,95 \% \mathrm{Cl}, 1.1-8.1)$, D-dimer $>0.5 \mathrm{mg} / \mathrm{L}$ $(\mathrm{OR}, 2.3,95 \% \mathrm{Cl}, 1.1-4.8)$, and albumin $<35 \mathrm{~g} / \mathrm{L}(\mathrm{OR}, 2.5,95 \% \mathrm{Cl}, 1.2-5.3)$ were identified to be risk factors of DVT in closed patella fracture. Among the DVTs, 30 cases (85.7\%) occurred in the injured extremity, 3 cases (8.6\%) in bilateral extremities, and 2 cases (5.7\%) solely in the uninjured extremity.

Conclusion: The prevalence of preoperative DVT in closed patella fracture was 4.4\%, with 3.2\% for distal and 1.2\% for proximal DVT. We recommend individualized risk stratification and early anticoagulation for patients with risk factors (age $\geq 65$ years, D-dimer $>0.5 \mathrm{mg} / \mathrm{L}$ and albumin $<35 \mathrm{~g} / \mathrm{L}$ ).
\end{abstract}

Keywords: Preoperative, DVT, Patella fracture, Risk factor

\section{Background}

Patella fracture, a kind of intraarticular fracture, was reported to account for approximately $1-2.6 \%$ of fractures in adults, and the elderly above 60 years is a high incidence of the population, and there was an increasing trend with ages [1-3]. Most patella fractures need surgical treatment and a satisfactory outcome can

\footnotetext{
* Correspondence: tanzc123456@126.com

'Department of Orthopaedic Surgery, The 3rd Hospital of Hebei Medical University, NO.139 Ziqiang Road, Shijiazhuang 050051, Hebei, China

${ }^{3}$ Key Laboratory of Biomechanics of Hebei Province, Shijiazhuang 050051, Hebei, People's Republic of China

Full list of author information is available at the end of the article
}

be obtained through surgical treatment and postoperative rehabilitation [4]. DVT (deep vein thrombosis) is a dangerous complication in orthopedic patients that can lead to adverse clinical outcomes, such as life-threatening pulmonary embolism (PE). Preoperative DVT may cause a surgical delay in orthopedic patients, which would significantly increase postoperative morbidity and mortality and have an adverse effect on the quality of life [5-8]. Ignoring the progression of DVT in such a population often leads to a bad prognosis, while an early simple intervention often obtains a satisfactory outcome. 
Generally, plasma hypercoagulability after trauma, venous stasis, and injury of venous endothelium are believed to be predisposing factors of DVT [9]. In the specific clinical context, such as patella fracture in geriatric patients, immobilization of the knee and surgical delay due to comorbidities may predispose patients to DVT. DVTs in patients who underwent major orthopedic surgeries (total joint arthroplasty and hip and pelvic fracture surgery) have been extensively studied $[8,10,11]$. However, the detailed information on the prevalence, related risk factors, and locations of DVT in isolated lower limb fractures (ILLFs) has not been paid much attention to. There were few kinds of researches focusing on the DVT in ILLFs of different anatomical sites [12-15], and the incidence rates varied greatly between different locations. To our knowledge, the current study was the first study with an adequate size sample focusing on the preoperative DVT in closed patella fractures.

It is of great clinical significance to identify the risk factors of DVT and determine the optimal thromboprophylaxis. Although the predominant DVT in ILLFs is distal DVT [13-15], it has been reported that trauma-induced distal DVT can propagate proximally [16], significantly increasing the risk of life-threatening PE. Currently, controversy still exists on thromboprophylaxis in patients with ILLFs. Even the clinical guidelines of different countries are not consistent on this clinical issue $[17,18]$. In summary, the understanding of preoperative DVT in closed patella fractures is currently limited. Risk stratification of preoperative DVT in such a population has not been studied. Thus, the primary purpose of the study was to investigate the incidence and risk factors of preoperative DVT in closed isolated patella fractures and the secondary purpose was to investigate the locations of the DVT.

\section{Patients and methods}

This was a prospective study. The methods of the study were conducted in accordance with the STROCSS (Strengthening the Reporting of Cohort Studies in Surgery) guidelines. Approval from the ethics committee of our institution was acquired. All the participants had written informed consent. Patients who sustained acute closed patella fracture between January 1, 2016, and April 1, 2019, in the level-I trauma center were included. Blood analyses and ultrasonography of bilateral lower extremities were routinely performed. According to the empirical criteria, the sample size of logistic regression analysis should be 10 to 15 times the number of covariates. There were 33 covariates in this study, and the sample size should not be less than $33 \times 10=330$.

\section{Inclusion and exclusion}

Patients who met the following criteria were included: 1 . age > 18 years; 2 . diagnosis of closed isolated patella fracture; 3. with complete and available medical data. Patients with pathological fractures, old fractures (treatment delayed > 3weeks), and polytrauma were excluded. Besides, patients who were under anticoagulant treatment on admission for other illnesses were also excluded.

A total of 875 patients with unilateral patella fracture were admitted to our institution for surgery treatment between January 1, 2016, and April 1, 2019. Among these patients, 790 cases met the criteria and agreed to participate in the study, consisting of 469 males and 321 females, with a median age of 53 (interquartile range (IQR), 18 to 92). The participants were divided into two groups based on the occurrence of preoperative DVT: group 1 for DVT; group 2 for non-DVT (Fig. 1).

After admission, the injured limbs of the patients received splinting and were elevated appropriately. All the participants received pharmacotherapy (low molecular weight heparin, 2500-4100 IU once daily, subcutaneous injection).

\section{Diagnosis of DVT}

Duplex ultrasonography (DUS) was used to diagnose DVT. All the participants went through DUS of bilateral lower extremities at admission, subsequently every 3 days and any time when a DVT was suspected. The diagnostic criteria for DVT were non-compressed vein, lumen obstruction or filling defect, the lack of respiratory vibration above the knee vein segment, and inadequate flow augmentation to the calf [19]. Duplex ultrasound scanning included the common femoral vein, superficial femoral and deep femoral vein, popliteal vein, anterior tibial vein, posterior tibial vein, and common fibular vein. Blood clot located in the intermuscular vein (gastrocnemius veins and soleal veins) was excluded in this study. DVT that occurred in the popliteal vein and above was defined as proximal DVT. DVT that occurred below the popliteal vein was defined as distal DVT.

\section{Data collection}

The data we used in the study was from a database, which was set up to prospectively investigate the complications in patients with different fractures in the institution. The detailed medical data was prospectively collected using a standard chart.

The data included demographic variables, comorbidities, injury mechanism (low or high energy), fracture types (simple or comminuted), history of cerebral infarction, history of any surgery, total hospital stay, time from injury to DVT (time from injury to the initial diagnosis of DVT), and laboratory indexes at admission. Demographic variables included age, gender, body mass index (BMI), current smoking, alcohol consumption, and living place (urban or rural); comorbidities included hypertension, diabetes mellitus, ischemic heart disease, arrhythmia, and 


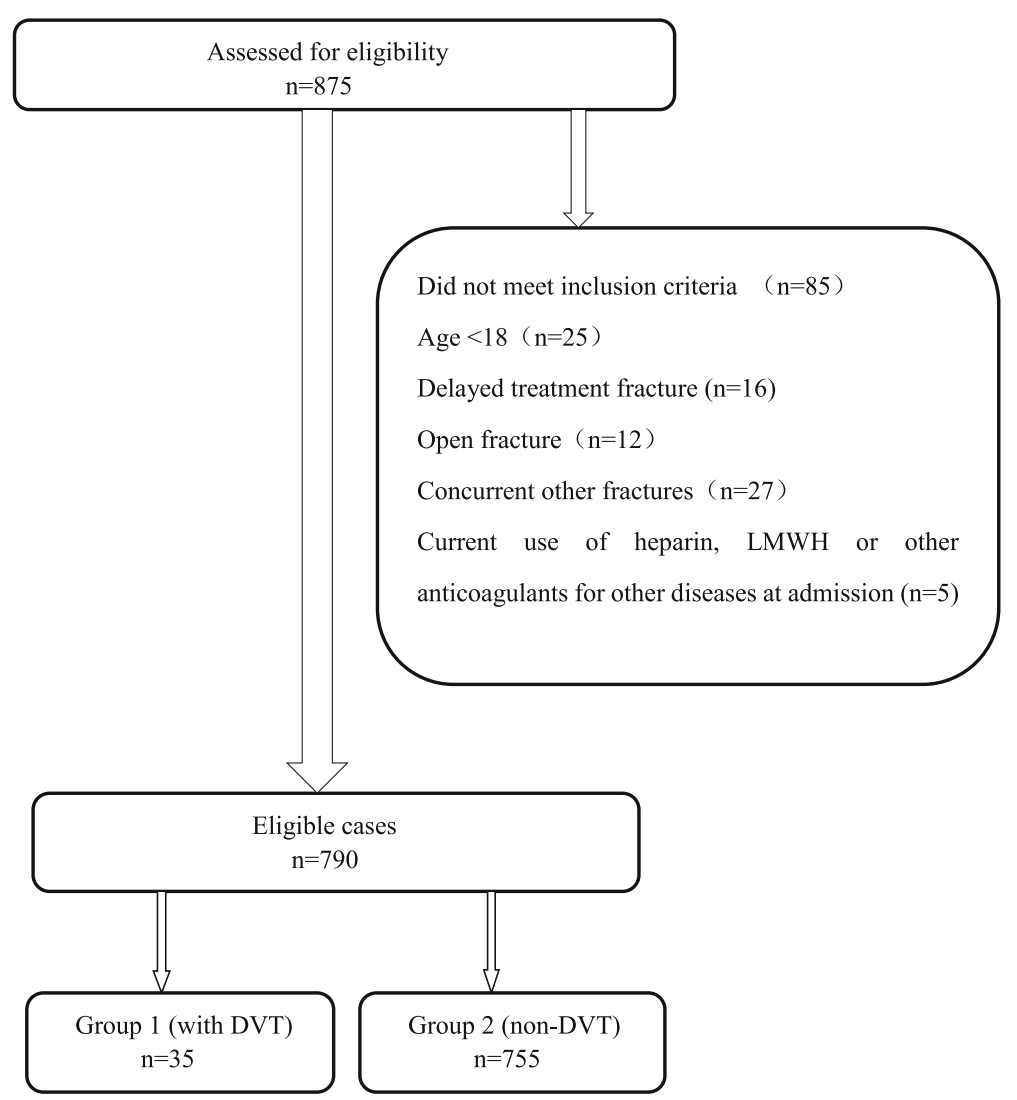

Fig. 1 Exclusion criteria and the eligible cases included in this study

chronic lung diseases. Fall while walking was defined as low-energy injury; other damages were regarded as highenergy injury. BMI was categorized into four groups: underweight $(<18.5)$, normal (18.5-23.9), overweight (24.0-27.9), and obesity ( $\geq 28.0$ ). Age was grouped into three categories: 18-44 years old, 45-64 years old, and above 65 years old. The laboratory indexes at admission included complete blood count and biochemical analysis.

\section{Statistical analysis}

Continuous variables were analyzed by Student's t test for independent samples or Mann-Whitney U test. Categorical variables were analyzed by chi-square or Fisher's exact test. Multivariate logistic regression analysis was used to identify the risk factors. OR (odds ratio) and 95\% CI (confidence interval) were used to express correlation strength. $P<0.05$ was set to be the statistical level. Hosmer-Lemeshow (H-L) test was performed to assess the fitting degree of the final model. The statistical software used in the study was SPSS22.0 (IBM, Armonk, New York, USA).

\section{Results}

Among the study cohort of 790 patients, 35 cases developed a preoperative DVT, indicating a prevalence of $4.4 \%$, with 25 cases $(3.2 \%)$ distal and 10 cases $(1.2 \%)$ proximal
DVT. Among the DVTs, 30 cases (85.7\%) occurred in the injured extremity, 3 cases $(8.6 \%)$ in bilateral extremities, and 2 cases $(5.7 \%)$ solely in the uninjured extremity. At the first Doppler ultrasound scanning after admission, no DVTs were found in the uninjured limbs. Compared with patients with non-DVT, patients with DVT had a longer total hospital stay $(8.7 \pm 2.1$ vs $13.9 \pm 1.3, P<0.05)$. The comparison results of variables between group 1 and group 2 were presented in Table 1. Significant differences were found in seven variables, including age category, injury mechanism (high energy), alcohol consumption, Ddimer $>0.5 \mathrm{mg} / \mathrm{L}$, albumin $<35 \mathrm{~g} / \mathrm{L}$, platelet $(\mathrm{PLT})>300$ $\times 10^{9} / \mathrm{L}$, and low-density lipoprotein cholesterol (LDL-C) $>$ $3.37 \mathrm{mmol} / \mathrm{L},(p<0.05)$. The seven variables were entered into the final model of the multivariate analysis and three variables were identified to be independent risk factors of the preoperative DVT in closed isolated patella fracture, including age $\geq 65$ years old, (OR, 3.0, 95\% CI, 1.1-8.1), Ddimer $>0.5 \mathrm{mg} / \mathrm{L}$, (OR, 2.3, 95\% CI, 1.1-4.8), and albumin $<35 \mathrm{~g} / \mathrm{L},(\mathrm{OR}, 2.5,95 \% \mathrm{CI}, 1.2-5.3)$, (Table 2). H-L Test revealed well fitness of the model $\left(\mathrm{X}^{2}=6.768, p=0.831\right)$.

\section{Discussion}

The current study firstly investigated the preoperative DVT in closed patella fracture. Based on the results of 
Table 1 Comparison between group 1 and group 2 in all variables collected

\begin{tabular}{|c|c|c|c|}
\hline Variables & Group $1(n=755)$ & Group $2(n=35)$ & $p$ \\
\hline & Number (\%) & Number (\%) & \\
\hline Gender(male) & $445(58.9)$ & $24(68.6)$ & .257 \\
\hline Age category & & & .003 \\
\hline $18<$ Age $\leq 44$ years & $242(32.1)$ & $8(22.9)$ & \\
\hline $45 \leq$ Age $<64$ years & $367(48.6)$ & $12(34.3)$ & \\
\hline Age $\geq 65$ years & $146(19.3)$ & $15(42.9)$ & \\
\hline $\mathrm{BMI}\left(\mathrm{kg} / \mathrm{m}^{2}\right)$ & & & .973 \\
\hline $18.5-23.9$ & $455(60.3)$ & $23(65.7)$ & \\
\hline$<18.5$ & $25(3.3)$ & $1(2.9)$ & \\
\hline $24.0-27.9$ & $202(26.8)$ & $8(22.9)$ & \\
\hline$\geq 28.0$ & $73(9.7)$ & $3(8.6)$ & \\
\hline Current smoking & $99(13.1)$ & $5(14.3)$ & .799 \\
\hline Alcohol consumption & $68(9.0)$ & $7(20.0)$ & .030 \\
\hline Living place (rural) & $392(51.9)$ & $20(57.1)$ & .545 \\
\hline Diabetes mellitus & $81(10.7)$ & $4(11.4)$ & .783 \\
\hline Hypertension & $167(22.1)$ & $8(22.9)$ & .918 \\
\hline Ischemic heart disease & $52(6.9)$ & $2(5.7)$ & .566 \\
\hline Arrhythmia & $34(4.5)$ & $3(8.6)$ & .222 \\
\hline Chronic lung diseases & $11(1.5)$ & $1(2.9)$ & .422 \\
\hline History of cerebral infarction & $34(4.5)$ & $3(8.6)$ & .222 \\
\hline History of any surgery & $130(17.2)$ & $4(11.4)$ & .372 \\
\hline Injury mechanism (high energy) & $91(12.1)$ & $10(28.6)$ & .009 \\
\hline Fracture type (comminuted) & $78(10.3)$ & $6(17.1)$ & .253 \\
\hline $\mathrm{TP}(<60 \mathrm{~g} / \mathrm{L})$ & $360(47.7)$ & $20(57.1)$ & .273 \\
\hline$A L B(<35 \mathrm{~g} / \mathrm{L})$ & $221(29.3)$ & $21(60.0)$ & .000 \\
\hline FBG (> $6.1 \mathrm{mmol} / \mathrm{L})$ & $228(30.2)$ & $9(25.7)$ & .571 \\
\hline $\mathrm{TC}(>5.2 \mathrm{mmol} / \mathrm{L})$ & $63(8.3)$ & $3(8.6)$ & .962 \\
\hline $\mathrm{TG}(>1.7 \mathrm{mmol} / \mathrm{L})$ & $160(21.2)$ & $6(17.1)$ & .565 \\
\hline LDL-C (> $3.37 \mathrm{mmol} / \mathrm{L})$ & $205(27.2)$ & $15(42.9)$ & .043 \\
\hline $\operatorname{VLDL}(>0.78 \mathrm{mmol} / \mathrm{L})$ & $158(20.9)$ & $6(17.1)$ & .589 \\
\hline $\mathrm{HDL}-\mathrm{C}(<1.1 \mathrm{mmol} / \mathrm{L})$ & $206(27.3)$ & $11(31.4)$ & .591 \\
\hline $\mathrm{WBC}\left(>10 \times 10^{9} / \mathrm{L}\right)$ & $152(20.1)$ & $6(17.1)$ & .666 \\
\hline NEUT $\left(>6.3 \times 10^{9} / L\right)$ & $268(35.5)$ & $8(22.9)$ & .125 \\
\hline $\operatorname{LYM}\left(<1.1 \times 10^{9} / \mathrm{L}\right)$ & $121(16.0)$ & $6(17.1)$ & .860 \\
\hline RBC (< lower limit) & $167(22.1)$ & $7(20.0)$ & .767 \\
\hline HGB (< lower limit) & $174(23.0)$ & $6(17.1)$ & .416 \\
\hline HCT (< lower limit) & $141(18.7)$ & $6(17.1)$ & .820 \\
\hline $\operatorname{PLT}\left(>300 \times 10^{9} / \mathrm{L}\right)$ & $47(6.2)$ & $6(17.1)$ & .024 \\
\hline RDW (> 16.5\%) & $7(0.9)$ & $1(2.9)$ & .305 \\
\hline PDW (> 18.1\%) & $16(2.1)$ & $1(2.9)$ & .541 \\
\hline D-dimer (>0.5 mg/L) & $352(46.6)$ & $27(77.1)$ & .000 \\
\hline
\end{tabular}

$D V T$ deep venous thrombosis, $B M I$ body mass index, $R B C$ red blood cell, reference range: female, 3.5-5.0 $\times 10^{12} / L$, males, 4.0-5.5 $\times 10^{12} / \mathrm{L}, H G B$ hemoglobin, reference range: females, $110-150 \mathrm{~g} / \mathrm{L}$, males, $120-160 \mathrm{~g} / \mathrm{L}$, FBG fasting blood glucose, HCT hematocrit, $40-50 \%$, WBC white blood cell, NEUT neutrophile, LYM lymphocyte, PLT platelet, 100-300 $\times 10^{9} / \mathrm{L}, T P$ total protein, ALB albumin, $R D W$ red cell distribution width, PDW platelet distribution width, TC total cholesterol, TG triglyceride, LDL-C low-density lipoprotein cholesterol, HDL-C high-density lipoprotein cholesterol, VLDL very-low-density lipoprotein 
Table 2 Multivariate analyses of risk factors associated with preoperative DVT in closed isolated patella fracture

\begin{tabular}{lll}
\hline Risk factors & OR $(\mathbf{9 5} \% \mathrm{Cl})$ & $\boldsymbol{P}$ value \\
\hline D-dimer $(>0.5 \mathrm{mg} / \mathrm{L})$ & $2.3(1.1-4.8)$ & .032 \\
Albumin $(<35 \mathrm{~g} / \mathrm{L})$ & $2.5(1.2-5.3)$ & .017 \\
Age category & & .045 \\
$18<$ Age $\leq 44$ years & Reference & \\
$45 \leq$ Age $<64$ years & & .624 \\
Age $\geq 65$ years old & $3.0(1.1-8.1)$ & .028 \\
\hline
\end{tabular}

the study, we found that the prevalence of preoperative DVT in closed patella fracture was $4.4 \%$, with $3.2 \%$ distal and $1.2 \%$ proximal DVT. Three variables, including age $>65$ years, D-dimer $>0.5 \mathrm{mg} / \mathrm{L}$, and albumin $<35 \mathrm{~g} / \mathrm{L}$ were identified to be independent risk factors of DVT in closed patella fracture.

Studies focusing on the incidence of DVT in patella fractures were currently limited; only two studies investigated the prevalence of DVT in patella fractures; neither evaluated the potential risk factors of DVT. Jared et al. [15] conducted a retrospective study to estimate the annual incidence of thrombotic events in 30 days in different lower limb fractures from 2008 to 2018; he found the overall incidence of DVT in patella fracture was $0.6 \%$. In his study, all the DVTs were symptomatic, while asymptomatic DVTs were not included, which may account for the lower incidence of DVT in his study. Wang et al. [14] conducted a research to investigate the perioperative DVT rate in specific isolated lower extremity fractures, in which a small sample of 59 patients with patella fracture was included. The overall preoperative DVT rate in patella fracture was $15.3 \%$ (9/59), including proximal DVT $(1.7 \%, 1 / 59)$ and distal DVT $(13.6 \%, 8 /$ 59), which is much higher than that of the current study. Blood clots located in the intermuscular veins were excluded in the current study, while included in the study of Wang et al. [14], which may account for the wide difference of the DVT rate between the two researches.

In the current study, $85.7 \%$ of the DVTs occurred in the injured legs, $8.6 \%$ in bilateral legs, and $5.7 \%$ solely in the uninjured extremity. The results indicated that DVT in closed isolated patella fracture could occur in both injured and uninjured legs and there is a tendency of higher incidence in the injured legs. The finding was similar to some previous researches [20]. Wang et al. [14] reported that $83.6 \%$ of the DVTs were located in the injured extremity, $5.4 \%$ in the bilateral extremity, and $11.0 \%$ solely in the uninjured extremity in patients with isolated lower limb fracture. Niu et al. [21] found that $76.1 \%$ of the DVTs solely involved the injured leg, 9.0\% involved bilateral legs, and $14.9 \%$ solely involved the uninjured legs in the geriatric patients with a femoral neck fracture. However, some studies got slightly different results. Shuang et al. [22] reported that in patients with lower extremity fractures, $60 \%$ of the preoperative DVTs were located in bilateral legs and $40 \%$ were solely located in the uninjured legs. Immobilization of the injured legs and vascular endothelial injury caused by fractures may account for the predominant rate of DVT that occurred in the injured legs.

We also found that the majority of the DVTs in closed patella fracture were distal DVT. In contrast with this, the rate of proximal DVT in the hip was much higher $[8,11,21,23]$. This demonstrated that the location of DVT may be associated with the fracture anatomical sites, the more proximal to the hip of the fracture site, the higher risk of the proximal DVT.

Old age has been well demonstrated to be a risk factor of DVT among orthopedic patients by previous studies [24]. Park et al. [25] reported that an advanced age above 60 years was a significant predictor of DVT in patients with fractures below the hip. In a prospective cohort study, Zhang et al. [26] reported that age over 65 years was associated with the formation of preoperative DVT in distal femur fractures. Goel et al. [27] found age $>40$ years was an independent predictor for DVT following fractures below the knee. Zhang et al. [28] conducted a retrospective study and found that age was a significant risk factor of preoperative DVT in hip fractures. Consistent with these studies, in the current study, we found age $\geq 65$ years was a significant risk factor of preoperative DVT in closed patella fracture. We recommend routine anticoagulation and preoperative DVT screening in elderly patients above 65 years with patellar fractures.

D-dimer, a specific degradation product derived from fibrinolytic cross-linked fibrin clots, has been widely applied as a predictor of DVT in patients. The diagnosis value of $\mathrm{D}$-dimer in thrombotic events has been well established [29, 30]. Though D-dimer indicates higher sensitivity, the specificity is low. Some researchers demonstrated that the combination of age and D-dimer as a critical value significantly improved the accuracy of prediction for the occurrence of DVT [31, 32]. Reagh et al. [33] found that D-dimer levels had differences between males and females; however, there was no significant difference in optimal cutoff value for excluding DVT between genders. The current study confirmed that an elevated level of D-dimer (>0.5 mg/L) was correlated with an increased risk of DVT in closed patella fractures.

Serum albumin level is an indicator of nutritional status. Albumin less than $35 \mathrm{~g} / \mathrm{L}$ is defined as hypoalbuminemia [34]. Serum albumin level plays an important role in patients' prognosis in many medical contexts. Preoperative albumin level was an important indicator for preoperative evaluation of complications and 
prognosis in orthopedic patients [35]. Hypoalbuminaemia was reported to be an important trigger factor in the elevation of fibrinogen and platelet aggregability, which can be reversed by infusing albumin [36, 37]. In a prospective study, Ma et al [12] found that albumin < $35 \mathrm{~g} / \mathrm{L}$ was an independent risk factor of DVT in lower limb fracture. Lung et al. [38] reported lower serum albumin was significantly correlated with an increased rate of DVT in patients who underwent total shoulder arthroplasty. Consistent with these studies, in the current study, we found that low albumin $<35 \mathrm{~g} / \mathrm{L}$ was an independent risk factor of DVT in closed patella fracture. Hypoalbuminemia was a modifiable risk factor of DVT in such a population; we recommend preoperative screening and correction of nutritional status in patients with patella fracture, though the optimal strategy for correcting serum albumin levels to reduce the risk of DVT remains uncertain and further studies are needed.

Some inherent limitations existed in the current study. First, this was a single-center study; there may be a selection bias of the study cohort, and further multicenter studies are necessary. Second, like other multivariate analyses, we could not include every potential risk factor in the study and some potential risk factors might be missed. Third, data on the variable of comorbidity were collected based on the self-report of the patient, and this may influence the accuracy of the data. Fourth, the participants in the study were all inpatients for surgical treatment; those outpatients were not involved; thus, there may be a selection bias to some extent.

\section{Conclusion}

The prevalence of preoperative DVT in closed patella fracture was $4.4 \%$, with $3.2 \%$ for distal and $1.2 \%$ for proximal DVT. We recommend individualized risk stratification and early anticoagulation for patients with high-risk factors (age $\geq 65$ years, D-dimer $>0.5 \mathrm{mg} / \mathrm{L}$, albumin $<35 \mathrm{~g} / \mathrm{L}$ ).

\section{Acknowledgements}

We are grateful to Junyong Li, Kuo Zhao, and Junzhe Zhang of the Department of Orthopedics for their kind assistance.

\section{Authors' contributions \\ Yingze Zhang designed the study. Zhongzheng Wang collected the data of interest. Yuchuan Wang searched relevant literature. Hongzhi Hu analyzed and interpreted the data. Zhanchao Tan wrote the manuscript, and Yingze Zhang approved the final version of the manuscript. The authors read and approved the final manuscript.}

\section{Availability of data and materials}

All the data will be available upon motivated request to the corresponding author of the present paper.

\section{Declarations}

\section{Ethics approval and consent to participate}

This study was approved by the ethics committee of the 3rd hospital of Hebei Medical University. Informed consent was obtained from all the participants.
Consent for publication

Written informed consent was obtained from each patient to authorize the publication of their data.

\section{Competing interests}

The authors declare that they have no competing interests.

\section{Author details}

'Department of Orthopaedic Surgery, The 3rd Hospital of Hebei Medical University, NO.139 Ziqiang Road, Shijiazhuang 050051, Hebei, China. ${ }^{2}$ Department of Orthopedics, Union Hospital of Tongji Medical College of Huazhong University of Science and Technology, Wuhan 430022, China. ${ }^{3}$ Key Laboratory of Biomechanics of Hebei Province, Shijiazhuang 050051, Hebei, People's Republic of China. ${ }^{4} \mathrm{NHC}$ Key Laboratory of Intelligent Orthopaedic Equipment, The Third Hospital of Hebei Medical University, Shijiazhuang, China.

Received: 12 April 2021 Accepted: 15 June 2021

Published online: 23 June 2021

\section{References}

1. Court-Brown CM, Caesar B. Epidemiology of adult fractures: a review. Injury. 2006;37(8):691-7. https://doi.org/10.1016/j.injury.2006.04.130.

2. Zhu Y, Liu S, Chen W, Wang L, Zhang X, Zhang Y. Socioeconomic factors and individual lifestyles influencing the incidence of patella fractures: a national population-based survey in China. Int Orthop. 2019;43(3):687-95. https://doi.org/10.1007/s00264-018-3985-9.

3. Larsen P, Court-Brown CM, Vedel JO, Vistrup S, Elsoe R. Incidence and epidemiology of patellar fractures. Orthopedics. 2016;39(6):e1154-8. https:// doi.org/10.3928/01477447-20160811-01.

4. Henrichsen JL, Wilhem SK, Siljander MP, Kalma JJ, Karadsheh MS. Treatment of patella fractures. Orthopedics. 2018;41(6):e747-55. https://doi.org/10.392 8/01477447-20181010-08.

5. Johnson-Lynn S, Ngu A, Holland J, Carluke I, Fearon P. The effect of delay to surgery on morbidity, mortality and length of stay following periprosthetic fracture around the hip. Injury. 2016;47(3):725-7. https://doi.org/10.1016/j. injury.2015.11.013.

6. Muhm M, Arend G, Ruffing T, Winkler H. Mortality and quality of life after proximal femur fracture-effect of time until surgery and reasons for delay. Eur J Trauma Emerg Surg. 2013;39(3):267-75. https://doi.org/10.1007/s00068013-0267-5.

7. Weller I, et al. The effect of hospital type and surgical delay on mortality after surgery for hip fracture. J Bone Joint Surg Br. 2005;87(3):361-6.

8. Song $K$, Yao $Y$, Rong Z, Shen $Y$, Zheng M, Jiang $Q$. The preoperative incidence of deep vein thrombosis (DVT) and its correlation with postoperative DVT in patients undergoing elective surgery for femoral neck fractures. Arch Orthop Trauma Surg. 2016;136(10):1459-64. https://doi.org/1 0.1007/s00402-016-2535-4.

9. Wolberg AS, Rosendaal FR, Weitz JI, Jaffer $1 H$, Agnelli G, Baglin T, et al. Venous thrombosis. Nat Rev Dis Primers. 2015;1(1):15006. https://doi.org/1 0.1038/nrdp.2015.6.

10. Lotke PA, Steinberg ME, Ecker ML. Significance of deep venous thrombosis in the lower extremity after total joint arthroplasty. Clin Orthop Relat Res. 1994;299:25-30.

11. Moed BR, Miller JR, Tabaie SA. Sequential duplex ultrasound screening for proximal deep venous thrombosis in asymptomatic patients with acetabular and pelvic fractures treated operatively. J Trauma Acute Care Surg. 2012; 72(2):443-7. https://doi.org/10.1097/TA.0b013e318241090d.

12. Zhu Y, Chen W, Li J, Zhao K, Zhang J, Meng H, et al. Incidence and locations of preoperative deep venous thrombosis (DVT) of lower extremity following tibial plateau fractures: a prospective cohort study. J Orthop Surg Res. 2021;16(1):113. https://doi.org/10.1186/s13018-021-02259-y.

13. Williams JR, Little MTM, Kramer PA, Benirschke SK. Incidence of preoperative deep vein thrombosis in calcaneal fractures. J Orthop Trauma. 2016;30(7): e242-5. https://doi.org/10.1097/BOT.0000000000000568.

14. Wang $H$, Kandemir U, Liu P, Zhang H, Wang PF, Zhang BF, et al. Perioperative incidence and locations of deep vein thrombosis following specific isolated lower extremity fractures. Injury. 2018;49(7):1353-7. https:// doi.org/10.1016/j.injury.2018.05.018.

15. Warren JA, Sundaram K, Hampton R, Billow D, Patterson B, Piuzzi NS. Venous thromboembolism rates remained unchanged in operative lower 
extremity orthopaedic trauma patients from 2008 to 2016. Injury. 2019; 50(10):1620-6. https://doi.org/10.1016/j.injury.2019.09.003.

16. Iskander $\mathrm{GA}$, et al. Incidence and propagation of infrageniculate deep venous thrombosis in trauma patients. J Trauma. 2006;61(3):695-700. https://doi.org/10.1097/01.ta.0000210453.70742.7f.

17. Falck-Ytter Y, Francis CW, Johanson NA, Curley C, Dahl OE, Schulman S, et al. Prevention of VTE in orthopedic surgery patients: antithrombotic therapy and prevention of thrombosis, 9th ed: American College of Chest Physicians evidence-based clinical practice guidelines. Chest. 2012;141(2 Suppl):e278S325S. https://doi.org/10.1378/chest.11-2404.

18. Lai J, Ma S, Wang Y, Cai Z, Hu J, Wei N, et al. Factors associated with mental health outcomes among health care workers exposed to coronavirus disease 2019. JAMA Netw Open. 2020;3(3):e203976. https://doi.org/10.1001/ jamanetworkopen.2020.3976.

19. Gornik HL, Sharma AM. Duplex ultrasound in the diagnosis of lowerextremity deep venous thrombosis. Circulation. 2014;129(8):917-21. https:// doi.org/10.1161/CIRCULATIONAHA.113.002966.

20. Decker S, Weaver MJ. Deep venous thrombosis following different isolated lower extremity fractures: what is known about prevalences, locations, risk factors and prophylaxis? Eur J Trauma Emerg Surg. 2013;39(6):591-8. https:// doi.org/10.1007/s00068-013-0266-6.

21. Niu S, Li J, Zhao Y, Ding D, Jiang G, Song Z. Preoperative deep venous thrombosis (DVT) after femoral neck fracture in the elderly, the incidence, timing, location and related risk factors. BMC Musculoskelet Disord. 2021; 22(1):264. https://doi.org/10.1186/s12891-021-04145-4.

22. Qu SW, et al. Deep vein thrombosis in the uninjured lower extremity: a retrospective study of 1454 patients with lower extremity fractures. Clin Appl Thromb Hemost. 2021;27:1076029620986862.

23. Lee SY, Ro DH, Chung CY, Lee KM, Kwon SS, Sung KH, et al. Incidence of deep vein thrombosis after major lower limb orthopedic surgery: analysis of a nationwide claim registry. Yonsei Med J. 2015;56(1):139-45. https://doi. org/10.3349/ymj.2015.56.1.139.

24. Tan L, Qi B, Yu T, Wang C. Incidence and risk factors for venous thromboembolism following surgical treatment of fractures below the hip: a meta-analysis. Int Wound J. 2016;13(6):1359-71. https://doi.org/10.1111/ iwj.12533.

25. Park SJ, Kim CK, Park YS, Moon YW, Lim SJ, Kim SM. Incidence and factors predicting venous thromboembolism after surgical treatment of fractures below the hip. J Orthop Trauma. 2015;29(10):e349-54. https://doi.org/10.1 097/BOT.0000000000000336.

26. Zhang J, Zhao K, Li J, Meng H, Zhu Y, Zhang Y. Age over 65 years and high levels of C-reactive protein are associated with the risk of preoperative deep vein thrombosis following closed distal femur fractures: a prospective cohort study. J Orthop Surg Res. 2020;15(1):559. https://doi.org/10.1186/s13 018-020-02089-4.

27. Goel DP, et al. Prophylaxis of deep-vein thrombosis in fractures below the knee: a prospective randomised controlled trial. J Bone Joint Surg Br. 2009; 91(3):388-94.

28. Zhang BF, Wei X, Huang H, Wang PF, Liu P, Qu SW, et al. Deep vein thrombosis in bilateral lower extremities after hip fracture: a retrospective study of 463 patients. Clin Interv Aging. 2018;13:681-9. https://doi.org/1 $0.2147 / C \mid A . S 161191$.

29. Wells PS, Anderson DR, Rodger M, Forgie M, Kearon C, Dreyer J, et al. Evaluation of D-dimer in the diagnosis of suspected deep-vein thrombosis. N Engl J Med. 2003;349(13):1227-35. https://doi.org/10.1056/NEJMoa023153.

30. Bjøri E, Johnsen HS, Hansen JB, Braekkan SK. D-dimer at venous thrombosis diagnosis is associated with risk of recurrence. J Thromb Haemost. 2017; 15(5):917-24. https://doi.org/10.1111/jth.13648.

31. Douma RA, Tan M, Schutgens REG, Bates SM, Perrier A, Legnani C, et al. Using an age-dependent D-dimer cut-off value increases the number of older patients in whom deep vein thrombosis can be safely excluded. Haematologica. 2012;97(10):1507-13. https://doi.org/10.3324/haematol.2011. 060657

32. Schouten HJ, Geersing GJ, Koek HL, Zuithoff NPA, Janssen KJM, Douma RA et al. Diagnostic accuracy of conventional or age adjusted D-dimer cut-off values in older patients with suspected venous thromboembolism: systematic review and meta-analysis. Bmj. 2013;346(may03 1):f2492. https:// doi.org/10.1136/bmj.f2492

33. Reagh JJ, Zheng H, Stolz U, Parry BA, Chang AM, House SL, et al. Sex-related Differences in D-dimer Levels for Venous Thromboembolism Screening. Acad Emerg Med. 2021. https://doi.org/10.1111/acem.14220.
34. Jaberi FM, Parvizi J, Haytmanek TC, Joshi A, Purtill J. Procrastination of wound drainage and malnutrition affect the outcome of joint arthroplasty. Clin Orthop Relat Res. 2008;466(6):1368-71. https://doi.org/10.1007/s11999008-0214-7.

35. Lee D, Lee R, Cross MT, Tran A, Kappa J, Moghtaderi S. Low serum albumin levels are associated with increased 30-day cardiopulmonary complications, reoperation, and readmission rates following total shoulder arthroplasty. lowa Orthop J. 2019;39(2):27-34.

36. Kim SB, et al. Effect of increasing serum albumin on haemostatic factors synthesized in the liver in CAPD patients. Nephrol Dial Transplant. 1998; 13(8):2053-8. https://doi.org/10.1093/ndt/13.8.2053.

37. Kim SB, Chi HS, Park JS, Hong CD, Yang WS. Effect of increasing serum albumin on plasma D-dimer, von Willebrand factor, and platelet aggregation in CAPD patients. Am J Kidney Dis. 1999;33(2):312-7. https:// doi.org/10.1016/S0272-6386(99)70306-9.

38. Lung BE, Kanjiya S, Bisogno M, Komatsu DE, Wang ED. Risk factors for venous thromboembolism in total shoulder arthroplasty. JSES Open Access. 2019;3(3):183-8. https://doi.org/10.1016/j.jses.2019.07.003.

\section{Publisher's Note}

Springer Nature remains neutral with regard to jurisdictional claims in published maps and institutional affiliations.
Ready to submit your research? Choose BMC and benefit from:

- fast, convenient online submission

- thorough peer review by experienced researchers in your field

- rapid publication on acceptance

- support for research data, including large and complex data types

- gold Open Access which fosters wider collaboration and increased citations

- maximum visibility for your research: over $100 \mathrm{M}$ website views per year

At BMC, research is always in progress.

Learn more biomedcentral.com/submissions 